\title{
The role of neutrophils during intestinal inflammation
}

\author{
BM Fournier ${ }^{1}$ and CA Parkos ${ }^{1}$
}

Polymorphonuclear leukocytes or neutrophils play a critical role in the maintenance of intestinal homeostasis. They have elegant defense mechanisms to eliminate microbes that have translocated across a single layer of mucosal epithelial cells that form a critical barrier between the gut lumen and the underlying tissue. During the inflammatory response, neutrophils also contribute to the recruitment of other immune cells and facilitate mucosal healing by releasing mediators necessary for the resolution of inflammation. Although the above responses are clearly beneficial, excessive recruitment and accumulation of activated neutrophils in the intestine under pathological conditions such as inflammatory bowel disease is associated with mucosal injury and debilitating disease symptoms. Thus, depending on the circumstances, neutrophils can be viewed as either good or bad. In this article, we summarize the beneficial and deleterious roles of neutrophils in the intestine during health and disease and provide an overview of what is known about neutrophil function in the gut.

\section{INTRODUCTION}

Polymorphonuclear leukocytes (PMN), also called neutrophils, are the most abundant leukocyte population in the blood, comprising $50-60 \%$ of the circulating leukocytes $\left(25 \times 10^{9}\right.$ cells $) .{ }^{1}$ PMN are critical components of the innate immune response that are essential in protecting the host from microbial pathogens, while also minimizing deleterious effects mediated by dying or injured cells (reviewed in Amulic et al. ${ }^{2}$ ). PMN are elegantly adapted to perform a variety of antimicrobial functions such as degranulation and phagocytosis (Figure 1). ${ }^{2}$ Indeed, neutrophils are uniquely capable of forming massive amounts of reactive oxygen species and other toxic molecules that effectively destroy pathogens. Upon PMN contact with invading microbes, reactive oxygen species are generated in an oxidative burst by an nicotinamide adenine dinucleotide phosphate (NADPH) oxidase consisting of a multi-subunit enzyme complex that is assembled on the membrane (Figure 1) (Cross and Segal ${ }^{3}$ and reviewed in Babior ${ }^{4}$ and Petry et al. $\left.{ }^{5}\right)$. Another component of the PMN antibacterial arsenal consists of different pools of intracellular granules that contain antimicrobial peptides $(\alpha$-defensins and cathelicidins), myeloperoxidase, hydrolytic enzymes (lysozyme, sialidase, and collagenase), proteases (cathepsin G, azurocidin, and elastase), cationic phospholipase, and metal chelators (lactoferrin) that are released upon contact with microbes. ${ }^{6}$ Finally, PMN are capable of imprinting the tissue with antimicrobial "prisons" termed neutrophil extracellular traps (NETs) (Figure 1). ${ }^{7}$ NETs have been extensively investigated in recent years as it is now appreciated that this newly described function is a critical component of the neutrophil killing arsenal (reviewed in Papayannopoulos and Zychlinsky ${ }^{8}$ ). Invading microorganisms are sequestered in these NETs composed of nuclear contents (DNA and chromatin) mixed with toxic molecules from intracellular granules and the cytosol and effectively destroyed. ${ }^{7,9}$ Although many of the details underlying formation of NETs are still unclear, it appears that NET production is linked to disappearance of nuclear and granule membranes and production of reactive oxygen species. ${ }^{8} \mathrm{NET}$ production is thus associated with major cellular alterations in PMN that include loss of nuclei. This results in a unique form of neutrophil cell death termed "NETosis" that is distinct from apoptosis or necrosis. ${ }^{10,11}$

As highlighted above, PMN are a vital component of the innate immune system and comprise a critical component of the army of first responsers to sites of inflammation. ${ }^{1,2}$ Although it is clear that PMN function is essential throughout the body, this review will focus on the role of PMN in intestinal inflammation. Specifically, we provide an overview of the differential roles of neutrophils in intestinal homeostasis and disease and highlight factors known to participate in PMN recruitment during intestinal inflammation.

\footnotetext{
${ }^{1}$ Epithelial Pathobiology Research Unit, Department of Pathology and Laboratory Medicine, Emory University School of Medicine, Atlanta, Georgia, USA. Correspondence: B Fournier (bfourni@emory.edu) or CA Parkos (cparkos@emory.edu) 


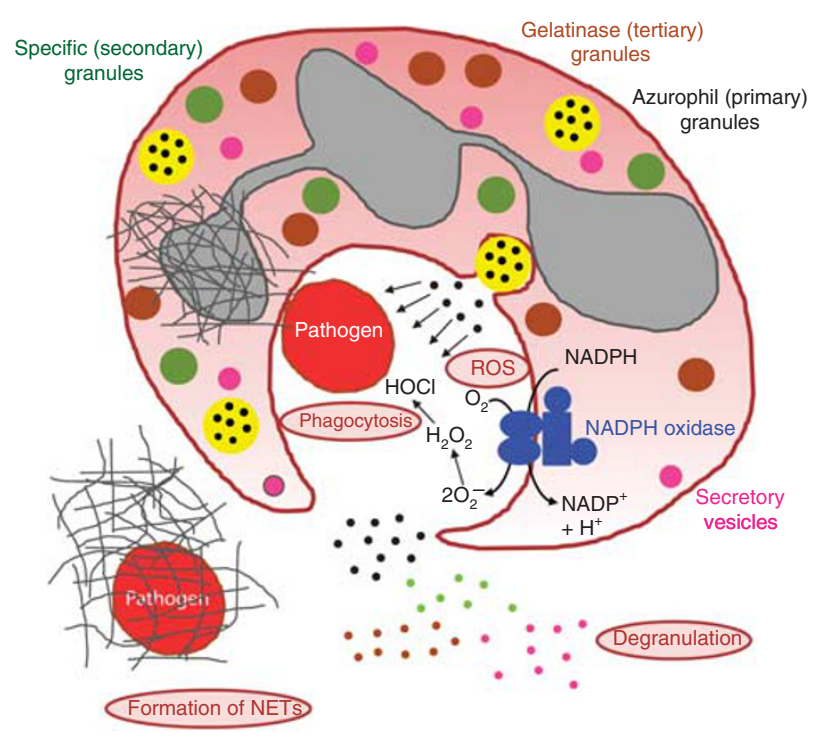

Figure 1 Neutrophils contain a potent antimicrobial arsenal. The nicotinamide adenine dinucleotide phosphate (NADPH) oxidase produces reactive oxygen species (ROS), e.g., hydrogen peroxide $\left(\mathrm{H}_{2} \mathrm{O}_{2}\right)$, hypochlorite ion $\left(\mathrm{OCl}^{-}\right)$, and superoxide anion $\left(\mathrm{O}_{2}^{-}\right)$in the phagolysosome during phagocytosis. Various intracellular granules (azurophil or primary, specific or secondary, gelatinase or tertiary, and secretory granules) containing potent antimicrobial agents are also released in the phagolysosome or in the extracellular space through degranulation. Finally, neutrophil extracellular traps (NETs) are also produced during polymorphonuclear leukocytes activation. (Adapted from Cross and Segal, ${ }^{3}$ Papayannopoulos and Zychlinsky, ${ }^{8}$ Quinn et al., ${ }^{176}$ and Faurschou and Borregard. ${ }^{177}$ )

\section{A PARADOX: THE BENEFICIAL AND DETRIMENTAL ROLES OF PMN DURING INTESTINAL INFLAMMATION}

Homeostatic regulation of the intestine is complex and involves a delicate equilibrium to limit inflammation despite intimate contact with massive numbers of commensal bacteria present in the lumen. Three major components contribute to gut homeostasis, including the epithelium, intestinal microbes, and immune cells. A single layer of intestinal epithelial cells (IECs) forms a protective physical barrier against commensal microflora present in the lumen. ${ }^{12}$ It is now well established that the epithelium works in coordination with microflora and immune cells to maintain intestinal homeostasis. ${ }^{13}$

During intestinal inflammation, resident monocytes contribute to the recruitment of neutrophils through production of macrophage-derived chemokines. ${ }^{14,15}$ Neutrophils present in the blood sense the chemoattractant gradient and traverse the vascular endothelium to reach the intestinal lamina propria. As part of the normal gut inflammatory response, neutrophils are recruited to sites of infection or inflammatory stimuli within minutes, and the response peaks by 24-48 hours. Under certain physiological or pathological conditions, neutrophils cross the epithelium into the intestinal lumen. Upon reaching the inflammatory site, neutrophils selectively release monocyte chemoattractants, such as CAP18, cathepsin G, and azurocidin (reviewed in Soehnlein and Lindbom ${ }^{15}$ ). Thus, shortly after arrival of PMN to the mucosa, macrophages are recruited for a second-wave inflammatory response that ensues for the next several days.

Inflammatory bowel diseases (IBDs) such as ulcerative colitis (UC) and Crohn's disease (CD) have complex etiologies but are simply characterized by chronic active intestinal inflammation that waxes and wanes. The main features of these diseases are a robust inflammatory response of unknown origin associated with mucosal injury and increased epithelial permeability, invasion of commensal bacteria into the subepithelial space or lamina propria, and massive recruitment of neutrophils (reviewed in Maloy and Powrie ${ }^{13}$ ). The pathogenesis of IBD is thus clearly multifactorial and dependent on disruption of the epithelial barrier, dysregulation of the innate immune system responses to commensal flora, and defects in the adaptive immune system (reviewed in Kaser et al. ${ }^{16}$ ). However, the relative contributions of PMN to the pathogenesis of IBD is controversial with some studies describing a beneficial role, yet, others reporting pathological contributions from neutrophils. For example, some reports of studies using either rat or mouse models of colitis (dinitrobenzene sulfonic acid [DNBS], dextran sulphate sodium [DSS], and CD $4{ }^{+} \mathrm{CD} 45 \mathrm{RB}^{\text {high }}$ transfer) have demonstrated that neutrophil depletion exacerbates inflammation, suggesting that PMN have a beneficial role during colitis. ${ }^{17-19}$ In contrast, depletion of neutrophils in the rat using anti-neutrophil antibodies have been shown to ameliorate DSS- and 2,4,6-trinitronitrobenzene sulfonic acid (TNBS)-induced colitis. ${ }^{20-22}$ However, there are other studies using anti-neutrophil antibodies that have failed to demonstrate a role for neutrophils in the pathogenesis of particular models of experimental colitis in rats (acetic acid and phorbol-12-myristate-13-acetate). ${ }^{21,23}$ A discrepancy pertaining to the role of PMN in colitis has been noted in mouse studies where the different conclusions are assumed to be related, in part, to the use of anti-Gr1 antibody to deplete neutrophils. Specifically, anti-Gr1 antibodies appear to have systemic effects and not only bind to neutrophils but also to monocytes. ${ }^{24,25}$ In addition to differences in methods used to deplete neutrophils, it is also important to note that different rodent models of colitis are often used that require induction by markedly distinct mechanisms. Some models act by direct compromise of epithelial integrity (DSS and DNBS/TNBS-induced colitis), whereas others are a direct result of dysregulation of the immune system (CD45RB high transfer). ${ }^{26}$ To complicate matters further, some epithelial injury-based models such as DNBS/TNBS have been reported to mimic chronic intestinal inflammation, whereas others recapitulate acute colitis. ${ }^{27}$ The importance of such differences is highlighted in a neutrophildepletion study demonstrating no effect in PMA- and acetic acid-induced models, but effective amelioration of colitis induced by TNBS. ${ }^{21}$ Interestingly, the depletion of intestinal mononuclear phagocytes (macrophages and dendritic cells) has been reported to increase neutrophil infiltration and increase the severity of injury in the DSS-induced colitis model. However, when both neutrophils and mononuclear phagocytes were depleted, colitis did not worsen, suggesting that neutrophils are deleterious in the absence of mononuclear cells during intestinal inflammation. Thus, intestinal mononuclear cells clearly have a 
role in regulating neutrophil infiltration during colitis, and these observations highlight the interdependence of PMN function with other immune cells during colitis. ${ }^{28}$ These findings are in keeping with current dogma that neutrophils and macrophages interact sequentially in the inflammatory process (reviewed in Soehnlein and Lindbom ${ }^{15}$ ). Although the specific role of neutrophils during colitis has not been clearly delineated, it is clear that the role of neutrophils in regulating intestinal inflammation depends on the conditions and model used. Thus, additional studies are sorely needed to better understand neutrophil contributions to pathological intestinal inflammation.

\section{NEUTROPHIL FUNCTION INTHE INTESTINE DURING HEALTH AND DISEASE}

PMN as an antimicrobial weapon that protects the mucosa

The primary function of neutrophils in the gut is to kill luminal microbes that translocate across the epithelium and invade the mucosa. A good example of the importance of PMN in clearing invading microbes is the enhanced translocation of bacteria observed in colitic mice that have been depleted of PMN. ${ }^{17}$ However, conditions associated with disruption of epithelial barrier leading to increased translocation of commensal bacteria into the mucosa does not necessarily predispose individuals to pathological intestinal inflammation. Indeed, mice lacking junctional adhesion molecule (JAM)-A, a tight junction-associated protein expressed in IECs, have increased epithelial permeability and enhanced translocation of bacteria across the intestinal mucosa but do not get spontaneous colitis despite having increased levels of PMN in the sub-epithelial space or lamina propria. ${ }^{29}$ Presumably, increased recruitment of PMN to the lamina propria and/or some as yet unknown adaptive immune compensatory mechanisms serve a protective role in this situation. However, such compensatory mechanisms are lost under conditions of pathological intestinal inflammation as in IBD. Indeed, it has been observed that increased intestinal permeability results in a significantly increased numbers of commensal bacteria in the colonic mucosa of IBD patients compared with normal individuals. ${ }^{30}$ Furthermore, analysis of granulomas in CD revealed the presence of Escherichia coli DNA in $80 \%$ of patients, suggesting that mucosal-infiltrated bacteria may have a role in the inflammatory process. ${ }^{31}$ Insufficient numbers of functional PMN in the intestine during times of increased bacterial invasion might thus predispose to disease. In support of this, it appears that the number of PMN required to prevent bacterial multiplication in tissues is much higher than in the blood. Furthermore, the tissue surveillance capacity of neutrophils depends on the density of the neutrophils rather than the concentration of bacteria. ${ }^{32}$

Not only is the density of neutrophils in the tissue critical to keep luminal bacteria from gaining access to the body, the composition of the microflora also has a critical role in gut homeostasis as disturbance of this balance is associated with pathological intestinal inflammation. It is known that alterations in the composition of colonic microflora are present in patients with IBD (reviewed in Kaur et al. ${ }^{33}$ ). Furthermore, germ-free mice lacking these bacteria in the gut have exacerbated acute injury during DSS-induced colitis compared with conventionally raised mice. ${ }^{34}$ Colonization with commensal flora from wild-type mice results in the amelioration of colitis symptoms, suggesting that gut microbiota protect against colitis. ${ }^{34}$ These findings are in keeping with an important function of the microbiota to decrease colonization from bacterial pathogens and therefore prevent or, at least, diminish pathogen invasion (reviewed in Ashida et al. $^{35}$ ). Indeed, alterations in the commensal flora in patients with IBD is associated with increased risk of acquiring infection from intestinal pathogens. The above observations indicate that intestinal bacteria have a key role in regulating the inflammatory response, which is critically dependent on PMN, not only to keep excess translocation of commensal bacteria in check, but also to fight against invasion by pathogens that have gained a foothold under conditions of disease.

PMN are not only well suited to kill bacteria but the antimicrobial arsenal they possess can also contribute to an exacerbated inflammatory response. For example, Pentraxin 3, which is a component of specific neutrophil granules and NETs, is an antimicrobial protein released after PMN activation. It functions as a pattern-recognition molecule with opsonic activity involved in humoral immunity ${ }^{36,37}$ and has been shown to prevent neutrophil extravasation and recruitment though interaction with P-selectin on endothelial cells. ${ }^{38}$ In UC, pentraxin 3 has been mainly found in crypt abscesses, and its expression correlates with the histological grade of the disease. Although the exact role of pentraxin 3 in colitis is not fully understood, it has been proposed to participate in the pathology of crypt abscesses. ${ }^{36}$ Elastase is an example of a PMN azurophil granule constituent that has potent antimicrobial activity as a serine esterase and may also contribute to pathological inflammation in IBD. Anti-elastase therapy, for example, results in improvement of DSS- and TNBS-induced colitis in the rat. ${ }^{39}$ Not surprisingly, elevated elastase levels have also been reported in stool samples of patients with IBD. ${ }^{40}$ Another potent antimicrobial function of PMN that has been reported to have a role in pathological intestinal inflammation is the generation of reactive oxygen species from the neutrophil NADPH oxidase. Interestingly, it has been reported that mice lacking functional $\mathrm{Gp} 91^{\text {phox }}$, one of the membrane-bound proteins of NADPH oxidase, exhibit less mucosal injury in a DSS-induced model of colitis. ${ }^{41}$ By contrast, mice lacking Gp47 $7^{\text {phox }}$, one of the cytosolic proteins of NADPH oxidase, do not exhibit protection compared with wild-type mice during DSS-induced colitis, suggesting that these two components of NADPH oxidase may have different functions during colitis. ${ }^{42}$ From these examples it is apparent that PMN can act as double-edged sword in that both contribute to intestinal homeostasis through the elimination of unwanted pathogens and also participate in harmful inflammatory processes and can exacerbate the inflammation owing to the release of toxic granule contents and pro-inflammatory molecules. ${ }^{43}$

\section{PMN directly contribute to immune cell recruitment and activation in the gut}

The production of cytokines and mediators involved in inflammation and cellular immune responses by PMN is highly 
relevant for intestinal inflammatory disease and has been extensively explored in recent years. ${ }^{44}$ Neutrophils secrete significant amounts of pro-inflammatory cytokines such as CXCL8 and anti-inflammatory cytokines, including interleukin (IL)-10 during intestinal inflammation. ${ }^{44-46}$ Interestingly, it has been recently reported that PMN are capable of producing IL-17, ${ }^{47}$ which has been widely implicated in pathological intestinal inflammation. ${ }^{48}$ PMN-derived IL-17 has also been implicated in murine kidney ischemia-reperfusion injury, ${ }^{49}$ suggesting that IL-17 production by intestinal PMN may have a role in gut inflammation.

Neutrophils also produce matrix metalloproteases (MMPs), which are involved in the cleavage of chemokine precursors that have critical roles in cell recruitment. MMP-9 or gelatinase $\mathrm{B}$, present in PMN tertiary granules, is able to cleave several chemokines, thereby mediating inactivation (growth-regulated oncogene- $\alpha$ (GRO- $\alpha$ ) and platelet factor 4$)$ or increasing their potency (CXCL-1 and CXCL-8)..$^{50}$ Similarly, MMP-8 produced by PMN and macrophages cleaves CXCL-5 and CXCL-8, promoting their activation. ${ }^{51}$ Thus, $\mathrm{PMN}$ can potently affect inflammatory conditions through the secretion or modification of cytokines and chemokines that have important roles in the recruitment of additional effector cells.

Another potential contribution of PMN to pathological immune cell activation includes the ability to acquire antigenpresenting function during colitis, an intriguing event previously reported during other inflammatory diseases such as rheumatoid arthritis. ${ }^{52} \mathrm{PMN}$ isolated from inflamed colon in a model of adoptive transfer of $\mathrm{CD} 4{ }^{+} \mathrm{T}$ cells were reported to express major histocompatibility complex-II and CD86, usually present on antigen-presenting cells such as macrophages or dendritic cells but not on PMN. Such neutrophils were capable of inducing in vitro $\mathrm{CD} 4^{+} \mathrm{T}$ cell activation in an major histocompatibility complex-II- and antigen-dependent manner. ${ }^{25}$ Although these findings have not been confirmed in other colitis models or in human disease, it is intriguing that PMN might contribute to the pathogenesis of colitis by activating $\mathrm{T}$ cells.

\section{How neutrophil transepithelial migration participates in the pathogenesis of colitis}

Trafficking of neutrophils out of the circulation towards the intestine is a critical component of the inflammatory response. Indeed, selectins, integrins, and adhesion molecules have been abundantly associated with intestinal inflammation (reviewed in Rivera-Nieves et al. ${ }^{53}$ ). To reach the intestinal lumen, PMN must first exit the circulation, migrate across the lamina propria and finally cross the epithelial barrier. ${ }^{1,54}$ We will not focus on the proximal event of PMN transendothelial transmigration or parameters resulting from microvascular deficits, but rather on transepithelial migration, as disease symptoms correlate more strongly with migration of PMN across the intestinal epithelium under conditions of pathological intestinal inflammation. However, it is relevant to mention that neutrophil transmigration across the intestinal epithelium is distinct from that of transendothelial migration. For example, one obvious difference is the absence of shear force during transepithelial migration, which is a critical component of selectin-mediated interactions between PMN and endothelial cells (recently reviewed in Borregaard ${ }^{55}$ and Woodfin et al. ${ }^{56}$ ). Like transendothelial migration, PMN migration across the intestinal epithelium is a multistep process involving sequential interactions with IECs. In particular, PMN first bind to the IEC basolateral surface through interactions with the neutrophil $\beta 2$ integrin CD11b/CD18 (also called Mac-1 or CR3; Figure 2). ${ }^{57}$ Although basolateral epithelial ligand(s) for $\mathrm{CD} 11 \mathrm{~b} / \mathrm{CD} 18$ have not been defined, proteins decorated in sulfated fucose appear to be important. ${ }^{58}$ Furthermore, it is well appreciated that antibodies against CD11b decrease transepithelial transmigration. ${ }^{57} \mathrm{PMN}$ must next negotiate the paracellular space between epithelial cells, which presents a vital barrier owing to the presence of well-developed tight junctions (Figure 2). ${ }^{12}$ Although this aspect of PMN transepithelial migration is poorly understood, a few of the molecular interactions are known. For example, the rate of PMN migration is likely regulated in part by interactions between PMNexpressed signal-regulatory protein $\alpha$ and CD47 expressed on the basolateral membrane of IECs. ${ }^{54,59,60}$ At the level of the tight junction, binding interactions between a PMN-expressed JAM-like molecule and a related tight junction protein termed Coxsackie and adenovirus receptor partially mediate transmigration across epithelial tight junctions (Figure 2). ${ }^{61}$ It should be pointed out that this latter step is crucial in the development of pathological intestinal inflammation as transmigrating neutrophils create microscopic gaps between epithelial cells, leading to decreased transepithelial resistance. ${ }^{62,63}$ Furthermore, massive PMN transmigration has been shown to alter cellular levels of tight junction proteins, thereby weakening the epithelial barrier and increasing epithelial permeability ${ }^{64}$ Neutrophils may also release elastase that partially disrupts E-cadherin-mediated cell-cell contacts causing loss of epithelial barrier function. ${ }^{65}$ Loss of E-cadherin has been shown to result in activation of $\beta$-catenin signaling and modulation of epithelial repair. ${ }^{66}$ In addition, loss of barrier function secondary to disruption of cell-cell junctions worsens inflammation by facilitating translocation of bacteria from the lumen to the mucosa and inducing further PMN transmigration.

PMN transepithelial migration has also been shown to regulate expression of the MMP ADAM17, which cleaves the inactive precursor of tumor necrosis factor (TNF) $\alpha$ to form the active cytokine. This MMP is regulated by tissue inhibitor of metalloproteinase 3 (TIMP3) (reviewed in Scheller et al. ${ }^{67}$ ). Interestingly, both neutrophil transepithelial migration and treatment of epithelial cells with TNF $\alpha$ have been shown to increase epithelial ADAM17 and TIMP3 expression. ${ }^{68}$ However, there are distinct differences in the time courses of ADAM17 and TIMP3 expression during PMN transepithelial migration. In particular, increased ADAM17 expression is early, rapid, and transient after PMN transepithelial migration, whereas increased TIMP3 expression occurs at later time points. ${ }^{68}$ Furthermore, ADAM17, but not TIMP3, expression is increased in the inflamed colonic mucosa of individuals with active CD ${ }^{68,69}$ This increase correlates with the histological severity of inflammation and number of PMN observed in the mucosa. ${ }^{68}$ These results suggest that 


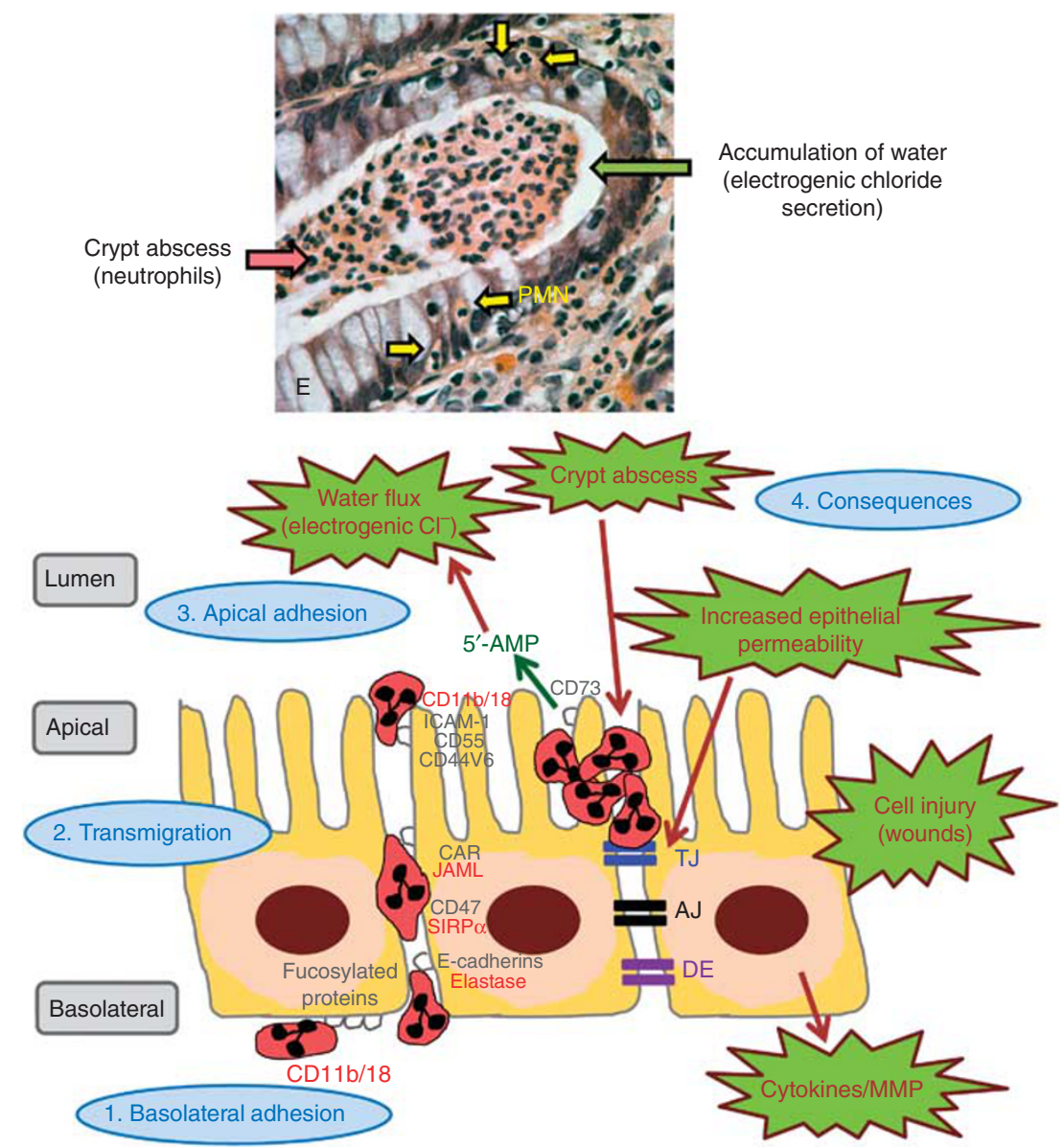

Figure 2 The various steps of transepithelial migration (basolateral adhesion, transmigration, and apical adhesion) and pathological consequences of massive polymorphonuclear leukocytes (PMN) migration across intestinal epithelium (blue text). Epithelial proteins important in PMN transepithelial migration are highlighted in grey text whereas key neutrophil proteins are in red text. The photomicrograph on the top half of the figure shows a crypt abscess (red arrow) from a patient with ulcerative colitis (kindly provided by Kevin Fisher MD, PhD). The crypt epithelium (E) is being infiltrated by transmigrating PMN (yellow arrows). Water accumulation within crypts (green arrow) is the result of stimulated electrogenic chloride secretion. AJ, adherens junctions (contain E-cadherin); AMP, adenosine monophosphate; CAR, Coxsackie and adenovirus receptor; DE, desmosomes; ICAM, intercellular adhesion molecule; JAML, junctional adhesion molecule (JAM)-like molecule; MMP, matrix metalloprotease; SIRP, signal-regulatory protein; TJ, tight junctions (contain CAR). (Adapted from Chin and Parkos ${ }^{54}$ ).

TNF $\alpha$ activation is promoted during the acute phase of inflammation and may be repressed during the chronic phase. Since PMN transepithelial migration is a central component of the acute inflammatory process, it likely has an important role in ADAM17 activation and production of TNF $\alpha$ during intestinal inflammation. Thus, PMN transepithelial migration also contributes to intestinal inflammation by stimulating the production of inflammatory cytokines by means of MMP.

After PMN have crossed epithelial tight junctions, a late stage in the transepithelial migration response involves interactions with luminal or apical surfaces of IECs (Figure 2). Here, PMN remain in intimate contact with IECs as part of crypt abscesses where they are exposed to both bacteria and a plethora of stimuli present in the lumen that result in neutrophil activation (Figure 2). ${ }^{54,70}$ Crypt abscesses, which are a classic feature of intestinal infection or active IBD, result from transmigration of massive numbers of activated neutrophils across tight junctions and accumulation within colonic epithelial crypts.
This process results in deformation of crypt architecture and disease symptoms (Figure 2). ${ }^{70}$

It is known that activated PMN produce abundant levels of $5^{\prime}$-adenosine monophosphate, which is converted to adenosine by an ectonucleotidase termed CD73 present on the apical surface of the colonic epithelium..$^{71}$ Adenosine then binds to its epithelial receptor $\mathrm{A} 2 \mathrm{~B}$ to stimulate electrogenic chloride transport and passive water flux. Such water transport is the basis of secretory diarrhea, a common feature of inflammatory conditions associated with PMN transmigration (Figure 2). ${ }^{71,72}$ Although much remains to be investigated, some of the receptors mediating adhesive interactions between PMN and the apical epithelial surface have been described. For example, intercellular adhesion molecule-1, one of the known ligands for neutrophil $\mathrm{CD} 11 \mathrm{~b} / \mathrm{CD} 18$, is expressed primarily on the apical surface of IECs under inflammatory conditions (Figure 2). ${ }^{73}$ Another IEC receptor for transmigrated PMN is CD55 or decay accelerating factor. Although the function of epithelial CD55 is not well 
understood, it is abundantly expressed on the apical membrane and appears to have a role in the release of apically attached PMN, thereby leading to epithelial clearance. ${ }^{74,75}$ Similarly, there are other complex interactions between transmigrated PMN and epithelial ligands on the apical membrane that mediate PMN detachment after proteolytic cleavage. Indeed, the v6 variant exon-containing form of CD44 is released from the apical surface of epithelial cells during PMN transepithelial migration and likely has an important role in regulation of PMN detachment. ${ }^{76}$ Clearly more work is needed to understand the role of these events in pathological intestinal inflammation.

\section{Role of PMN in mucosal wound healing}

A major debilitating feature of IBD is the persistence of mucosal epithelial wounds/ulcers secondary to an excessive inflammatory response. It is clear that during the acute inflammatory phase, PMN have a critical role in cleansing sites of injury by eliminating invading microbes. ${ }^{77}$ However, the cleansing process is associated with tissue injury and, although much has been learned about mechanisms of mucosal wounding, a similarly important aspect that deserves attention is the healing process. After injury, for intestinal mucosal healing to proceed, immune cells have a critical role in resolution events that restore tissue integrity. ${ }^{77}$

The resolution of inflammation requires that phagocytes exit along with efficient removal of inflammatory mediators and cell debris to restore homeostasis. ${ }^{78}$ There is now abundant evidence indicating that PMN have a crucial role during this particular phase of mucosal inflammation. Indeed, PMN produce or contribute to the biosynthesis of growth factors, such as vascular endothelial growth factor, and pro-resolution lipid mediators, such as lipoxins, resolvins, and protectins, that facilitate healing. ${ }^{77,79}$ They also participate in the phagocytosis of cell debris accumulating at the wound. ${ }^{80}$ Although PMN synthesize pro-inflammatory mediators, such as leukotrienes and prostaglandins, during the acute phase of inflammation, the synthetic pathway is switched to produce the potent anti-inflammatory molecule, lipoxin $\mathrm{A}_{4}$, during resolution (Figure 3) ${ }^{81}$ Lipoxin $\mathrm{A}_{4}$ has been shown to inhibit PMN recruitment and transepithelial migration..$^{82}$ Interestingly, patients with $\mathrm{UC}$ do not produce as much lipoxin $\mathrm{A}_{4}$ and 15-lipoxygenase as healthy controls. ${ }^{83}$ Furthermore, it has been shown that treatment with lipoxin $\mathrm{A}_{4}$ analogs decreases the severity of murine DSS- and TNBS-induced colitis. ${ }^{84,85}$

Neutrophils have also been reported to participate in the biosynthesis of resolvin E1 from eicosapentaenoic acid by providing 5-lipoxygenase to catalyze the second enzymatic reaction (Figure 3). ${ }^{86}$ Interestingly, resolvin $\mathrm{E} 1$ has been reported to associate with the leukotriene $\mathrm{B}_{4}\left(\mathrm{LTB}_{4}\right)$ receptor BLT1 present on neutrophils, resulting in downregulation of $\mathrm{LTB}_{4}$ activity. ${ }^{87}$ Similarly, docosohexaenoic acid is converted, through a series of enzymatic reactions, to protectin $\mathrm{D} 1$, and neutrophils contribute to this process with the 5-lipoxygenase involved in the second enzymatic reaction as highlighted in Figure 3. ${ }^{88-90}$ Resolvin E1 and protectin D1 both decrease neutrophil recruitment and enhance the phagocytosis of apoptotic neutrophils. ${ }^{91}$ Furthermore, these two lipid mediators have been shown to increase the expression of CC-chemokine receptor 5 on senescent neutrophils, therefore favoring elimination of the inflammatory CC-chemokine receptor 5 ligands CCL3 and CCL5. ${ }^{92}$ They also increase the expression of CD55 on the apical surface of IECs, resulting in the enhancement of PMN clearance (see

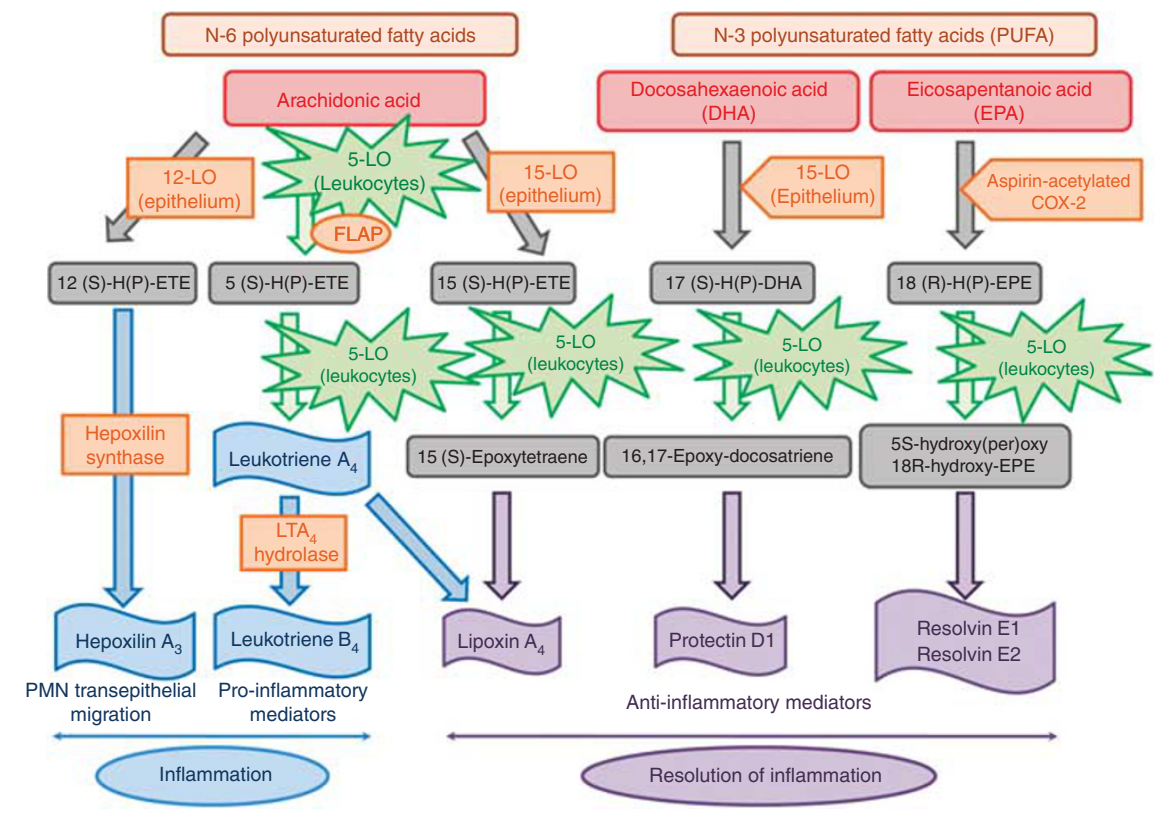

Figure 3 Biosynthetic pathways of pro- and anti-inflammatory mediators derived from polyunsaturated fatty acids involving 5-lipoxygenase (LO) from neutrophils. FLAP, 5-lipoxygenase-activating protein; $H(P)$-DHA, hydroxyperoxy docosahexanoic acid; $H(P)$-EPE, hydroxyperoxy eicosapentanoic acid; $\mathrm{H}(\mathrm{P})$-ETE, hydroxyperoxy eicosatetraenoic acid; $\mathrm{LTA}_{4}$, leukotriene $\mathrm{A}_{4} ; \mathrm{PMN}$, polymorphonuclear leukocytes. (Adapted from Wang and DuBois, ${ }^{156}$ Tjonahen et al., ${ }^{178}$ Serhan and Petasis, ${ }^{179}$ and Weylandt et al. ${ }^{180}$ ) 
Section on transepithelial migration). ${ }^{93}$ In vivo treatment with resolvin E1 has been shown to reduce colonic ulcerations, PMN infiltration, and inflammatory cytokine production, such as IL-12, resulting in the amelioration of colitis in a murine model of TNBS-induced colitis. ${ }^{94}$

A unique property of neutrophils that have exited the bloodstream is the cessation of proliferation, resulting in a short lifespan of just a few days. During the resolution phase of an acute inflammatory response, infiltrated neutrophils undergo apoptosis and are subsequently cleared by resident macrophages (reviewed in Kennedy and Deleo ${ }^{95}$ ). PMN undergoing apoptosis have diminished functional capacity but maintain membrane integrity and cytoplasmic contents until they are phagocytosed by tissue macrophages. ${ }^{96,97}$ Under conditions of persistent acute inflammation, such as active IBD, neutrophils continually accumulate within the intestinal mucosa and can overwhelm the capacity of scavenger cells..$^{98,99}$ Apoptotic neutrophils that are not eliminated by macrophages undergo secondary necrosis and release the contents of intracellular granules, which can induce pathological tissue damage. ${ }^{98,99}$ The proper elimination of senescent PMN is therefore an important and active physiological process during inflammation, particularly during the resolution phase. In the intestine, the process of PMN apoptosis can be delayed or accelerated by a number of factors. ${ }^{100}$ Bacterial lipopolysaccharide and several host-derived cytokines, including IL-1, IL-8, interferon- $\gamma$, C5a, and granulocyte-macrophage colony stimulating factor (GM-CSF), inhibit PMN apoptosis. By contrast, the cytokines IL-10 and TNF $\alpha$ as well as primary PMN functions, such as phagocytosis or respiratory burst, can induce apoptosis. ${ }^{101-107}$ Furthermore, transendothelial migration in response to the bacteria-derived chemoattractant formyl-methionylleucyl-phenylalanine (fMLF) enhances the effect of pro- or antiapoptotic molecules like TNF $\alpha$ or lipopolysaccharide. ${ }^{108,109}$ Interestingly, PMN transepithelial migration across T84 IECs in vitro has been shown to prevent PMN apoptosis, likely owing to shedding of Fas ligand, which is known to induce PMN apoptosis through the FAS (CD95) cell death receptor. ${ }^{105}$

Because neutrophil apoptosis is delayed in IBD patients, the findings described above are particularly relevant for pathological intestinal inflammation. ${ }^{110}$ It has been suggested that the delay in apoptosis observed in colitis is secondary to the abundant release of anti-apoptotic cytokines like GM-CSF as well as a decrease in caspase expression. ${ }^{110,111}$ Indeed GM-CSF production is increased during IBD. ${ }^{12}$ Intestinal perfusion fluids from individuals with UC have been found to delay PMN apoptosis in a GMCSF-dependent manner and enhance PMN migration in vitro. ${ }^{113}$ Furthermore, these effects are suppressed when patients are treated with corticosteroids. ${ }^{113}$ Although more mechanistic studies are needed, these findings suggest that GM-CSF is a key player in the regulation of neutrophil cell death during IBD.

\section{Defective neutrophil function is associated with pathological intestinal inflammation}

Although the etiology of IBD is multifactorial, there is considerable evidence linking defective neutrophil function to disease pathophysiology. For example, neutrophils from individuals with CD may have defective superoxide generation and phagocytosis. ${ }^{114-117}$ Such observations would also be expected to be associated with reduced clearance of mucosal bacteria, which could contribute to an excessive lymphocyte-mediated immune response. ${ }^{117}$ Furthermore, PMN dysfunction observed in CD appears to be associated with a defect in macrophage responses. In vitro and in vivo studies using macrophages from $\mathrm{CD}$ patients have shown lower production of pro-inflammatory cytokines compared with normal cells. ${ }^{118,119}$ Interestingly, neutrophil recruitment to traumatized skin and intestine in patients with $\mathrm{CD}$ is lower than in healthy individuals, which is likely due to poor production of PMN chemoattractants by macrophages. ${ }^{119}$ It is thus possible that a reduced acute inflammatory response with decreased PMN infiltration may contribute significantly to the pathological lymphocytic accumulation observed in CD. ${ }^{120,121}$

Primary defects in neutrophil function have been associated with inflammatory intestinal lesions that are similar to those observed in $\mathrm{CD}$. Chronic granulomatous disease is due to a lack of a functional NADPH oxidase and results in recurrent pyogenic infections that are often life-threatening. ${ }^{122,123}$ Interestingly, this disease is also characterized by abundant sterile granulomas in hollow organs such as the intestine. ${ }^{122}$ Indeed, $30 \%$ of chronic granulomatous disease patients have granulomatous colitis that is remarkably similar to what is observed in CD. ${ }^{121,124-126}$ Neutrophils from chronic granulomatous disease patients also generate less anti-inflammatory mediators, such as prostaglandin $\mathrm{D}_{2}$, and are more resistant to apoptosis. These findings suggest that PMN in chronic granulomatous disease may persist longer in tissues while producing more pro-inflammatory molecules than normal PMN. ${ }^{127}$ Other rare congenital disorders with abnormalities in neutrophil function also lead to IBD-like intestinal inflammation (reviewed in Yamamoto-Furusho and Korzenik ${ }^{120}$ ). For example, glycogen storage disease type 1 , which is characterized by a deficiency of the glucose-6-phosphate hydrolase system, is associated with neutrophil functional defects (neutropenia, decreased PMN chemotaxis, and reduced intracellular killing) and intestinal symptoms similar to those in CD (focal acute and chronic inflammation that is sometimes associated with cryptitis and/or granulomas). ${ }^{128,129}$ In addition, a patient with Chediak-Higashi syndrome, caused by a microtubule polymerization defect leading to decreased phagocytic activity, developed an intestinal complication with multiple ulcerations and stenotic lesions. ${ }^{130}$

An interesting report highlighted an important role for signal transducer and activator of transcription (STAT-3) in PMNmediated intestinal inflammation. STAT3, which translocates to the nucleus after leukocyte activation, is involved in regulation of cytokine production and is one of the transcriptional regulators involved in the IL-23 pathway identified as a susceptibility gene for IBD. ${ }^{131,132}$ The specific deletion of STAT3 in PMN and macrophages (LysMcre/Stat $3^{\text {flox/- }}$ ) has been reported to induce spontaneous chronic enterocolitis with increased infiltration of inflammatory cells (including PMN), crypt abscesses, 
mucosal ulcerations without granuloma formation, and thick-

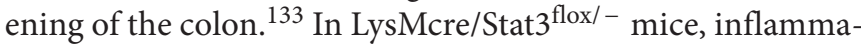
tory cytokine expression (TNF $\alpha$, IL-1, interferon- $\gamma$, and IL-6) is increased likely owing to a decrease of IL-10. It has been suggested that spontaneous colitis in these mice is due to constitutive activation of immune cells, including neutrophils and macrophages. ${ }^{133}$

The diminished expression of the anti-inflammatory cytokine IL-10 in the above Stat3-deficient mice supports the known role for this cytokine in regulating intestinal homeostasis. ${ }^{133}$ Indeed, neutrophils and macrophages are constitutively activated in IL-10-deficient mice. ${ }^{134}$ Although other parameters have clearly been implicated in the pathogenesis of spontaneous colitis of IL-10 $10^{-/}$mice, these results imply that PMN and macrophages may have a significant role. ${ }^{133,135,136}$ It thus appears that both functional deficiency and hyperactivation of neutrophils lead to colitis, which emphasizes the complex contributions of leukocytes to intestinal disease. ${ }^{43}$ Taken together, there is abundant evidence highlighting a critical role of active (but not over-active) neutrophils in regulating intestinal homeostasis while linking PMN dysfunction to pathological intestinal inflammation.

\section{REGULATION OF PMN RECRUITMENT/INFILTRATION DURING INTESTINAL INFLAMMATION Inflammatory mediators involved in PMN recruitment during intestinal inflammation}

The production of cytokines and chemokines by intestinal cells and other immune cells during intestinal inflammation is an important regulator of PMN recruitment and infiltration. For example, IL- 8 is a potent chemoattractant secreted by the basolateral surface of IECs and mediates PMN recruitment from the lamina propria to the epithelium ${ }^{137,138}$ but not across it. ${ }^{139}$ Importantly, IL-8 expression is increased during IBD where it is a major contributor to the increased numbers of PMN found in the mucosa (Ina et al. ${ }^{140}$ and reviewed in MacDermott $\left.{ }^{141}\right)$. Another important PMN chemokine, CXCL-1 or GRO- $\alpha$ has been shown to be essential for PMN recruitment during colitis. Indeed, mice lacking CXCL-1 are more susceptible to DSS-induced colitis. ${ }^{142}$ However, the colons in these mice had less PMN in the mucosa than those of wild-type mice, indicating that CXCL-1 is an important PMN chemoattractant. ${ }^{142}$

It is now well accepted that Il-17 derived from T helper 17 (Th17) cells has a significant role in intestinal homeostasis. IL-17A and IL-17F contribute to PMN recruitment by stimulating the secretion of chemokines (i.e., CXCL-8, CXCL-1, and CXCL-10), cytokines, and growth factors (i.e., TNF $\alpha$, IL-1 $\beta$, IL-6, GM-CSF, and G-CSF) from various cell types, including macrophages, epithelial cells, and fibroblasts. ${ }^{143-145}$ Furthermore, intestinal IL-17 production is increased in IBD $^{146-148}$ and IL-17A ${ }^{-/-}$and IL-17R $\mathrm{R}^{-/-}$mice are resistant to DSS- and TNBS-induced colitis. ${ }^{48,149,150}$ However, others have reported that the treatment of mice with anti-IL-17A antibody resulted in worse DSS-induced colitis and increased PMN infiltration in the colonic mucosa, which suggests beneficial effects of IL-17A. ${ }^{151}$ A recent immunofluorescence study showed co-localization of PMN and Th17 cells in inflamed colonic tissues from CD patients, suggesting that PMN interact closely with Th17 cells in this setting. ${ }^{152}$ It has also been shown that activated Th17 cells are able to directly recruit PMN by secreting CXCL-8. ${ }^{152}$ Whether by direct or indirect means, it is thus clear that TH17 cells and IL-17 are important in regulating PMN function in the intestine.

The complement component C5a is another potent PMN chemoattractant; however, despite abundant evidence for complement activation in IBD, ${ }^{153}$ the role of complement and, more specifically, C5a during colitis is not fully understood. Nevertheless, mice lacking the C5a receptor $\mathrm{C} 5 \mathrm{aR}$ are more resistant than wild-type controls to acute injury-induced colitis from DSS, which correlates with decreased PMN infiltration in the colon. ${ }^{154}$ Similarly, mice treated with a neutralizing anti-C5a antibody have reduced mucosal injury and evidence of decreased numbers of colonic PMN (myeloperoxidase activity) during the early stages (24 hours) of TNBS-induced colitis. ${ }^{155}$ Interestingly, in chronic models of DSS-induced colitis, $\mathrm{C} 5 \mathrm{aR}^{-1-}$ mice show differences in protection from disease progression depending on when measurements are taken. In particular, $\mathrm{C} 5 \mathrm{aR}^{-1-}$ mice appear to be more protected from chronic disease during first 25 days, after which clinical disease and colonic myeloperoxidase levels increase to levels higher than those of controls. ${ }^{154}$ These findings suggest complex roles for C5a during intestinal inflammation that involve deleterious effects during the acute phases of disease that may switch to a beneficial role during chronic disease.

Among the lipid mediators that attract PMN, $\mathrm{LTB}_{4}$ is an important chemoattractant in the gut. $\mathrm{LTB}_{4}$ belongs to the eicosanoid family and is synthesized from arachidonic acid (Figure 3). ${ }^{156}$ Notably, expression of three key enzymes involved in the leukotriene pathway (Figure 3; 5-lipoxygenase, 5-lipoxygenase-activating protein, and leukotriene $\mathrm{A}_{4}$ hydrolase) is significantly increased in the colonic mucosa of patients with active IBD, suggesting that, during IBD, an increase in $\mathrm{LTB}_{4}$ production may contribute to enhanced $\mathrm{PMN}$ infiltration. ${ }^{157}$ Furthermore, mice deficient in 5-lipoxygenase or wild-type mice treated with the 5-lipoxygenase inhibitor zileuton have a striking decrease in neutrophil myeloperoxidase activity in the colon that is associated with a significant reduction in colitis induced by DNBS and TNBS. ${ }^{158,159}$

Another arachidonic acid metabolite that is a potent PMN chemoattractant is hepoxilin $\mathrm{A}_{3}\left(\mathrm{HXA}_{3}\right)$, which is secreted in a polarized fashion by epithelial cells (Figure 3). ${ }^{160}$ In contrast to IL-8, $\mathrm{HXA}_{3}$ is released from the apical surface of the epithelium in response to invasion by pathogens like Salmonella. ${ }^{160}$ Although basolateral epithelial release of IL- 8 results in PMN accumulation in the subepithelial space, the apically-directed release of $\mathrm{HXA}_{3}$ is what serves as a driving force for transepithelial migration of PMN into the lumen. ${ }^{139}$ Consistent with the polarized release of $\mathrm{HXA}_{3}$, inhibition of the enzymatic machinery necessary for its production suppresses $\mathrm{HXA}_{3}$-mediated PMN transmigration. ${ }^{160}$ Thus, $\mathrm{HXA}_{3}$ is a potent chemoattractant that guides PMN through the epithelial layer. 
Regulation of PMN recruitment by bacteria-derived products It is well appreciated that bacterial products such as lipopolysaccharide, lipopoproteins, and DNA have potent effects on many intestinal cell types that result in a multitude of Nod and Toll-like receptor-mediated responses contributing to both homeostasis and pathological intestinal inflammation (reviewed in Cario ${ }^{161}$ and Werts et al. ${ }^{162}$ ). Bacteria also secrete products capable of directly attracting and/or activating PMN. The peptide $\mathrm{PMLF}$ is a potent PMN chemoattractant, and expression of this peptide receptor ( $\mathrm{N}$-formyl peptide receptor) has been reported to be increased in CD patients. ${ }^{163}$ Other peptides produced by both bacteria and viruses have been shown to activate $\mathrm{N}$-formyl peptide receptors present at the surface of PMN (reviewed in Rabiet et al. ${ }^{164}$ ). Furthermore, bacteria also produce short-chain fatty acids, such as acetate and butyrate, which are recognized by G-protein-coupled receptor 43 expressed on PMN and epithelial cells. ${ }^{165,166}$ Shortchain fatty acids are potent PMN chemoattractants in vitro; however, the role of G-protein-coupled receptor 43 for PMN infiltration during colitis is less clear in vivo, as results differ between studies. ${ }^{34,167}$ Nevertheless, Gpr43-1- mice exhibit increased mortality in acute and chronic models of DSSinduced colitis, and the use of bone marrow chimeric mice confirmed that immune cells, and not epithelial cells, were responsible for this effect. ${ }^{34,167}$

\section{Epithelial-derived metalloproteinases regulate PMN recruitment through activation of chemokines}

MMPs produced by IECs are zinc-dependent endoproteases that, in addition to degrading extracellular matrices, are also crucial for the proteolytic processing of PMN chemokines. ${ }^{168}$ Indeed, the expression of some MMPs is strikingly increased during intestinal inflammation. ${ }^{169-171}$ Treatment of IL-1 $\beta$ stimulated Caco-2 cells (human colon carcinoma cell line) with MMP-3 results in enhanced PMN, but not monocyte migration. ${ }^{172}$ This MMP-3-mediated chemotactic effect is due to the cleavage and activation of CXCL-7 (neutrophil-activating peptide 2). CXCL-7 is produced by IECs as the inactive precursor platelet basic protein and subsequently processed by MMP-3. ${ }^{172,173}$ Interestingly, both $\mathrm{mRNA}$ and protein levels of platelet basic protein/CXCL-7 are enhanced in patients with UC but not with CD. ${ }^{172}$

Another MMP, MMP-7 (matrilysin), is mainly produced by the intestinal epithelium and is known to generate $\alpha$-defensin. ${ }^{174}$ Mice lacking MMP-7 have delayed but sustained mucosal insult in an acute epithelial injury-induced model of DSS colitis. ${ }^{175}$ Furthermore, the amount and localization of PMN in colons of mice lacking MMP-7 are distinct from that in normal controls. ${ }^{175}$ In particular, PMN infiltration in wild-type mice was abundant 4 days post DSS, whereas only a few PMN were observed in colons of mice lacking MMP-7. Furthermore, MMP-7 ${ }^{-1}$ mice showed PMN infiltration localized primarily to the submucosa, whereas PMN from normal mice were distributed throughout the entire mucosa. ${ }^{175}$ The impaired PMN trafficking was determined to be secondary to decreased levels of key PMN chemoattractants, including macrophage inflammatory protein-2 and CXCL-8. Indeed, transiently increased levels of CXCL- 8 and macrophage inflammatory protein-2 found in lumenal lavage fluids from wild-type mice were not observed in MMP-7 ${ }^{-/-}$mice. ${ }^{175}$ These results suggest that MMP-7 regulates recruitment of $\mathrm{PMN}$ by modulating gradients of particular chemokines. How MMP-7 regulates macrophage inflammatory protein-2 and CXCL8 in the context of pathological intestinal inflammation requires further studies. Taken together, these examples highlight important

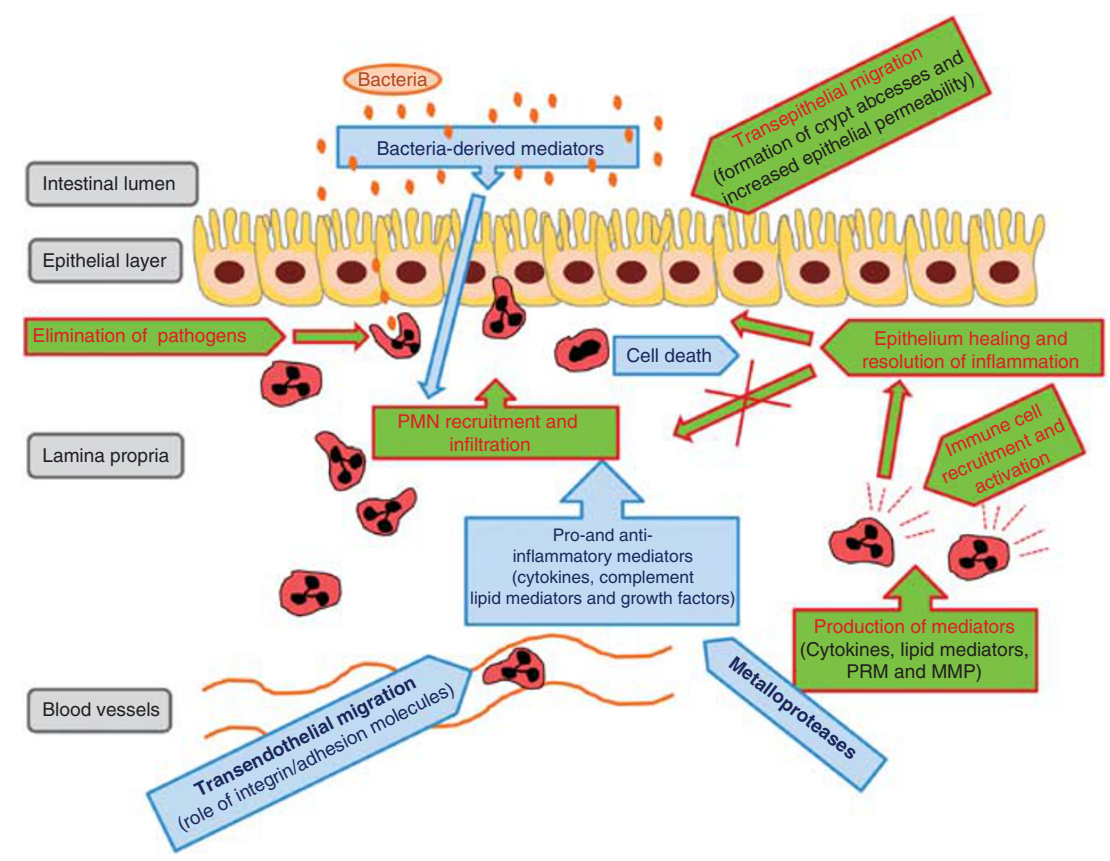

Figure 4 Neutrophil contributions and functions (red text) and factors influencing their recruitment/infiltration (blue) during intestinal inflammation. MMP, matrix metalloprotease; PMN, polymorphonuclear leukocytes; PRM, pattern recognition molecule (pentraxin 3). 
roles for MMPs in trafficking of PMN to the intestinal mucosa by regulating activity of chemokines.

\section{CONCLUDING REMARKS}

Although our knowledge of the roles of PMN during intestinal inflammation has increased considerably during recent years, the beneficial and detrimental contributions of PMN to this complex process remain controversial. Indeed, neutrophils are critical for mucosal homeostasis as it appears that disease is aggravated under certain conditions of PMN depletion. However, it is also clear that PMN directly contribute to disease pathology where excessive recruitment and activation leads to release of toxic products and massive transepithelial migration, resulting in crypt abscesses and extensive mucosal injury. The paradoxical yin and yang of PMN function during the intestinal inflammatory response is determined by crucial parameters, including the type of stimulus and generation of chemoattractants, which regulates the amount of PMN recruitment, the interaction of PMN with other immune cells that modulates PMN function, and the ability of the immune system to clear senescent PMN to effect resolution and healing (Figure 4). Thus, microbes and a multitude of cell types in the intestine serve to modulate PMN function under normal and inflammatory conditions. A better understanding of this complex interplay might provide new avenues for manipulating neutrophil function to treat pathological intestinal inflammation.

\section{ACKNOWLEDGMENTS}

We acknowledge funding from National Institutes of Health Grants DK079392 and DK072564 (C.A.P.), as well as a Senior Research Award from the CCFA sponsored by the Rodenberry Foundation (B.F.). We thank Kevin Fisher MD, PhD for the photomicrograph of a human crypt abscess.

\section{DISCLOSURE}

The authors declared no conflict of interest.

(c) 2012 Society for Mucosal Immunology

\section{REFERENCES}

1. Sadik, C.D., Kim, N.D. \& Luster, A.D. Neutrophils cascading their way to inflammation. Trends Immunol. 32, 452-460 (2011).

2. Amulic, B., Cazalet, C., Hayes, G.L., Metzler, K.D. \& Zychlinsky, A. Neutrophil function: from mechanisms to disease. Annu. Rev. Immunol. 30, 459-489 (2012).

3. Cross, A.R. \& Segal, A.W. The NADPH oxidase of professional phagocytes--prototype of the NOX electron transport chain systems. Biochim. Biophys. Acta. 1657, 1-22 (2004).

4. Babior, B.M. NADPH oxidase. Curr. Opin. Immunol. 16, 42-47 (2004).

5. Petry, A., Weitnauer, M. \& Gorlach, A. Receptor activation of NADPH oxidases. Antioxid. Redox. Signal. 13, 467-487 (2010).

6. Borregaard, N., Sorensen, O.E. \& Theilgaard-Monch, K. Neutrophil granules: a library of innate immunity proteins. Trends Immunol. 28, 340-345 (2007).

7. Brinkmann, V. et al. Neutrophil extracellular traps kill bacteria. Science 303, 1532-1535 (2004).

8. Papayannopoulos, V. \& Zychlinsky, A. NETs: a new strategy for using old weapons. Trends Immunol. 30, 513-521 (2009).

9. Urban, C.F. et al. Neutrophil extracellular traps contain calprotectin, a cytosolic protein complex involved in host defense against Candida albicans. PLoS Pathog. 5, e1000639 (2009).

10. Fuchs, T.A. et al. Novel cell death program leads to neutrophil extracellular traps. J. Cell. Biol. 176, 231-241 (2007).

11. Wartha, F. \& Henriques-Normark, B. ETosis: a novel cell death pathway. Sci. Signal. 1, pe25 (2008).
12. Koch, S. \& Nusrat, A. The life and death of epithelia during inflammation: lessons learned from the gut. Annu. Rev. Pathol. 7, 35-60 (2012).

13. Maloy, K.J. \& Powrie, F. Intestinal homeostasis and its breakdown in inflammatory bowel disease. Nature 474, 298-306 (2011).

14. Ajuebor, M.N. et al. Role of resident peritoneal macrophages and mast cells in chemokine production and neutrophil migration in acute inflammation: evidence for an inhibitory loop involving endogenous IL-10. J. Immunol. 162, 1685-1691 (1999).

15. Soehnlein, O. \& Lindbom, L. Phagocyte partnership during the onset and resolution of inflammation. Nat. Rev. Immunol. 10, 427-439 (2010).

16. Kaser, A., Zeissig, S. \& Blumberg, R.S. Inflammatory bowel disease. Annu. Rev. Immunol. 28, 573-621 (2010).

17. Kuhl, A.A. et al. Aggravation of different types of experimental colitis by depletion or adhesion blockade of neutrophils. Gastroenterology 133, 1882-1892 (2007).

18. Nemoto, Y. et al. Negative feedback regulation of colitogenic CD4 $4^{+}$ T cells by increased granulopoiesis. Inflamm. Bowel Dis. 14, 1491-1503 (2008).

19. Zhang, R. et al. Up-regulation of $\mathrm{Gr} 1^{+} \mathrm{CD} 11 \mathrm{~b}^{+}$population in spleen of dextran sulfate sodium administered mice works to repair colitis. Inflamm. Allergy Drug Targets 10, 39-46 (2011).

20. Natsui, M. et al. Selective depletion of neutrophils by a monoclonal antibody, RP-3, suppresses dextran sulphate sodium-induced colitis in rats. J. Gastroenterol. Hepatol. 12, 801-808 (1997).

21. Buell, M.G. \& Berin, M.C. Neutrophil-independence of the initiation of colonic injury. Comparison of results from three models of experimental colitis in the rat. Dig. Dis. Sci. 39, 2575-2588 (1994).

22. Kankuri, E. et al. Suppression of acute experimental colitis by a highly selective inducible nitric-oxide synthase inhibitor, $\mathrm{N}$-[3-(aminomethyl) benzyl]acetamidine. J. Pharmacol. Exp. Ther. 298, 1128-1132 (2001).

23. Yamada, T., Zimmerman, B.J., Specian, R.D. \& Grisham, M.B. Role of neutrophils in acetic acid-induced colitis in rats. Inflammation 15, 399-411 (1991).

24. Daley, J.M., Thomay, A.A., Connolly, M.D., Reichner, J.S. \& Albina, J.E. Use of Ly6G-specific monoclonal antibody to deplete neutrophils in mice. J. Leukoc. Biol. 83, 64-70 (2008).

25. Ostanin, D.V. et al. Acquisition of antigen-presenting functions by neutrophils isolated from mice with chronic colitis. J. Immunol. 188, 1491-1502 (2012).

26. Wirtz, S. \& Neurath, M.F. Mouse models of inflammatory bowel disease. Adv. Drug. Deliv. Rev. 59, 1073-1083 (2007).

27. Neurath, M.F., Fuss, I., Kelsall, B.L., Stuber, E. \& Strober, W. Antibodies to interleukin 12 abrogate established experimental colitis in mice. J. Exp. Med. 182, 1281-1290 (1995).

28. Qualls, J.E., Kaplan, A.M., van Rooijen, N. \& Cohen, D.A. Suppression of experimental colitis by intestinal mononuclear phagocytes. J. Leukoc. Biol. 80, 802-815 (2006).

29. Laukoetter, M.G. et al. JAM-A regulates permeability and inflammation in the intestine in vivo. J. Exp. Med. 204, 3067-3076 (2007).

30. Swidsinski, A. et al. Mucosal flora in inflammatory bowel disease. Gastroenterology 122, 44-54 (2002).

31. Ryan, P. et al. Bacterial DNA within granulomas of patients with Crohn's disease--detection by laser capture microdissection and PCR. Am. J. Gastroenterol. 99, 1539-1543 (2004).

32. Li, Y., Karlin, A., Loike, J.D. \& Silverstein, S.C. Determination of the critical concentration of neutrophils required to block bacterial growth in tissues. J. Exp. Med. 200, 613-622 (2004).

33. Kaur, N., Chen, C.C., Luther, J. \& Kao, J.Y. Intestinal dysbiosis in inflammatory bowel disease. Gut Microbes 2, 211-216 (2011).

34. Maslowski, K.M. et al. Regulation of inflammatory responses by gut microbiota and chemoattractant receptor GPR43. Nature 461, 1282-1286 (2009).

35. Ashida, H., Ogawa, M., Kim, M., Mimuro, H. \& Sasakawa, C. Bacteria and host interactions in the gut epithelial barrier. Nat. Chem. Biol. 8, 36-45 (2012).

36. Savchenko, A.S. et al. Long pentraxin 3 (PTX3) expression and release by neutrophils in vitro and in ulcerative colitis. Pathol. Int. 61, 290-297 (2011).

37. Mantovani, A., Garlanda, C., Doni, A. \& Bottazzi, B. Pentraxins in innate immunity: from C-reactive protein to the long pentraxin PTX3. J. Clin. Immunol. 28, 1-13 (2008). 
38. Deban, L. et al. Regulation of leukocyte recruitment by the long pentraxin PTX3. Nat. Immunol. 11, 328-334 (2010).

39. Nagao, Y., Miyata, H., Mizuguchi, K., Ban, M. \& Kato, K. [Effects of ulinastatin on experimental ulcerative colitis in rats]. Nihon Yakurigaku Zasshi 109, 41-52 (1997).

40. Adeyemi, E.O. \& Hodgson, H.J. Faecal elastase reflects disease activity in active ulcerative colitis. Scand. J. Gastroenterol. 27, 139-142 (1992).

41. Bao, S., Carr, E., Xu, Y.H. \& Hunt, N.H. Gp91phox contributes to the development of experimental inflammatory bowel disease. Immunol. Cell. Biol. 89, 853-860 (2011).

42. Krieglstein, C.F. et al. Regulation of murine intestinal inflammation by reactive metabolites of oxygen and nitrogen: divergent roles of superoxide and nitric oxide. J. Exp. Med. 194, 1207-1218 (2001).

43. Williams, I.R. \& Parkos, C.A. Colonic neutrophils in inflammatory bowel disease: double-edged swords of the innate immune system with protective and destructive capacity. Gastroenterology 133, 2049-2052 (2007).

44. Mantovani, A., Cassatella, M.A., Costantini, C. \& Jaillon, S. Neutrophils in the activation and regulation of innate and adaptive immunity. Nat. Rev. Immunol. 11, 519-531 (2011).

45. Raab, Y., Gerdin, B., Ahlstedt, S. \& Hallgren, R. Neutrophil mucosal involvement is accompanied by enhanced local production of interleukin-8 in ulcerative colitis. Gut 34, 1203-1206 (1993).

46. Nikolaus, S. et al. Increased secretion of pro-inflammatory cytokines by circulating polymorphonuclear neutrophils and regulation by interleukin 10 during intestinal inflammation. Gut 42, 470-476 (1998).

47. Ferretti, S., Bonneau, O., Dubois, G.R., Jones, C.E. \& Trifilieff, A. IL-17, produced by lymphocytes and neutrophils, is necessary for lipopolysaccharide-induced airway neutrophilia: IL-15 as a possible trigger. J. Immunol. 170, 2106-2112 (2003).

48. Hundorfean, G., Neurath, M.F. \& Mudter, J. Functional relevance of Thelper 17 (Th17) cells and the IL-17 cytokine family in inflammatory bowel disease. Inflamm. Bowel Dis. 18, 180-186 (2012).

49. Li, L. et al. IL-17 produced by neutrophils regulates IFN-gammamediated neutrophil migration in mouse kidney ischemia-reperfusion injury. J. Clin. Invest. 120, 331-342 (2010).

50. Van den Steen, P.E., Proost, P., Wuyts, A., Van Damme, J. \& Opdenakker, G. Neutrophil gelatinase B potentiates interleukin-8 tenfold by aminoterminal processing, whereas it degrades CTAP-III, PF-4, and GRO-alpha and leaves RANTES and MCP-2 intact. Blood 96, 2673-2681 (2000).

51. Tester, A.M. et al. LPS responsiveness and neutrophil chemotaxis in vivo require PMN MMP-8 activity. PLoS One 2, e312 (2007).

52. Iking-Konert, C. et al. Transdifferentiation of polymorphonuclear neutrophils to dendritic-like cells at the site of inflammation in rheumatoid arthritis: evidence for activation by T cells. Ann. Rheum. Dis. 64, 1436-1442 (2005).

53. Rivera-Nieves, J., Gorfu, G. \& Ley, K. Leukocyte adhesion molecules in animal models of inflammatory bowel disease. Inflamm. Bowel Dis. 14, 1715-1735 (2008).

54. Chin, A.C. \& Parkos, C.A. Pathobiology of neutrophil transepithelial migration: implications in mediating epithelial injury. Annu. Rev. Pathol. 2, 111-143 (2007).

55. Borregaard, N. Neutrophils, from marrow to microbes. Immunity $\mathbf{3 3}$, 657-670 (2010).

56. Woodfin, A., Voisin, M.B. \& Nourshargh, S. Recent developments and complexities in neutrophil transmigration. Curr. Opin. Hematol. 17, 9-17 (2010).

57. Parkos, C.A., Delp, C., Arnaout, M.A. \& Madara, J.L. Neutrophil migration across a cultured intestinal epithelium. Dependence on a CD11b/CD18-mediated event and enhanced efficiency in physiological direction. J. Clin. Invest. 88, 1605-1612 (1991).

58. Zen, K., Liu, Y., Cairo, D. \& Parkos, C.A. CD11b/CD18-dependent interactions of neutrophils with intestinal epithelium are mediated by fucosylated proteoglycans. J. Immunol. 169, 5270-5278 (2002).

59. Liu, Y. et al. The role of CD47 in neutrophil transmigration. Increased rate of migration correlates with increased cell surface expression of CD47. J. Biol. Chem. 276, 40156-40166 (2001).

60. Parkos, C.A. et al. CD47 mediates post-adhesive events required for neutrophil migration across polarized intestinal epithelia. J. Cell Biol. 132, 437-450 (1996).
61. Zen, K. et al. Neutrophil migration across tight junctions is mediated by adhesive interactions between epithelial coxsackie and adenovirus receptor and a junctional adhesion molecule-like protein on neutrophils. Mol. Biol. Cell 16, 2694-2703 (2005).

62. Nash, S., Stafford, J. \& Madara, J.L. Effects of polymorphonuclear leukocyte transmigration on the barrier function of cultured intestinal epithelial monolayers. J. Clin. Invest. 80, 1104-1113 (1987).

63. Nusrat, A., Parkos, C.A., Liang, T.W., Carnes, D.K. \& Madara, J.L. Neutrophil migration across model intestinal epithelia: monolayer disruption and subsequent events in epithelial repair. Gastroenterology 113, 1489-1500 (1997).

64. Kucharzik, T., Walsh, S.V., Chen, J., Parkos, C.A. \& Nusrat, A. Neutrophil transmigration in inflammatory bowel disease is associated with differential expression of epithelial intercellular junction proteins. Am. J. Pathol. 159, 2001-2009 (2001).

65. Ginzberg, H.H. et al. Neutrophil-mediated epithelial injury during transmigration: role of elastase. Am. J. Physiol. Gastrointest. Liver Physiol. 281, G705-G717 (2001).

66. Zemans, R.L. et al. Neutrophil transmigration triggers repair of the lung epithelium via beta-catenin signaling. Proc. Natl. Acad. Sci. USA 108, 15990-15995 (2011).

67. Scheller, J., Chalaris, A., Garbers, C. \& Rose-John, S. ADAM17: a molecular switch to control inflammation and tissue regeneration. Trends Immunol. 32, 380-387 (2011).

68. Cesaro, A. et al. Differential expression and regulation of ADAM17 and TIMP3 in acute inflamed intestinal epithelia. Am. J. Physiol. Gastrointest. Liver Physiol. 296, G1332-G1343 (2009).

69. Brynskov, J. et al. Tumour necrosis factor alpha converting enzyme (TACE) activity in the colonic mucosa of patients with inflammatory bowel disease. Gut 51, 37-43 (2002).

70. Xavier, R.J. \& Podolsky, D.K. Unravelling the pathogenesis of inflammatory bowel disease. Nature 448, 427-434 (2007).

71. Strohmeier, G.R. et al. Surface expression, polarization, and functional significance of CD73 in human intestinal epithelia. J. Clin. Invest. 99, 2588-2601 (1997).

72. Madara, J.L. et al. $5^{\prime}$-adenosine monophosphate is the neutrophilderived paracrine factor that elicits chloride secretion from T84 intestinal epithelial cell monolayers. J. Clin. Invest. 91, 2320-2325 (1993).

73. Parkos, C.A. et al. Expression and polarization of intercellular adhesion molecule-1 on human intestinal epithelia: consequences for CD11b/ CD18-mediated interactions with neutrophils. Mol. Med. 2, 489-505 (1996).

74. Louis, N.A., Hamilton, K.E., Kong, T. \& Colgan, S.P. HIF-dependent induction of apical CD55 coordinates epithelial clearance of neutrophils. FASEB J. 19, 950-959 (2005).

75. Lawrence, D.W. et al. Antiadhesive role of apical decay-accelerating factor (CD55) in human neutrophil transmigration across mucosal epithelia. J. Exp. Med. 198, 999-1010 (2003).

76. Brazil, J.C. et al. Neutrophil migration across intestinal epithelium: evidence for a role of CD44 in regulating detachment of migrating cells from the luminal surface. J. Immunol. 185, 7026-7036 (2010).

77. Sylvia, C.J. The role of neutrophil apoptosis in influencing tissue repair. J. Wound Care 12, 13-16 (2003).

78. Serhan, C.N., Chiang, N. \& Van Dyke, T.E. Resolving inflammation: dual anti-inflammatory and pro-resolution lipid mediators. Nat. Rev. Immunol. 8, 349-361 (2008).

79. Serhan, C.N. et al. Resolution of inflammation: state of the art, definitions and terms. FASEB J 21, 325-332 (2007).

80. Park, J.E. \& Barbul, A. Understanding the role of immune regulation in wound healing. Am. J. Surg. 187, 11S-16S (2004).

81. Levy, B.D., Clish, C.B., Schmidt, B., Gronert, K. \& Serhan, C.N. Lipid mediator class switching during acute inflammation: signals in resolution. Nat. Immunol. 2, 612-619 (2001).

82. Colgan, S.P., Serhan, C.N., Parkos, C.A., Delp-Archer, C. \& Madara, J.L. Lipoxin A4 modulates transmigration of human neutrophils across intestinal epithelial monolayers. J. Clin. Invest. 92, 75-82 (1993).

83. Mangino, M.J., Brounts, L., Harms, B. \& Heise, C. Lipoxin biosynthesis in inflammatory bowel disease. Prostaglandins Other Lipid Mediat. 79, 84-92 (2006).

84. Fiorucci, S. et al. A beta-oxidation-resistant lipoxin A4 analog treats hapten-induced colitis by attenuating inflammation and immune dysfunction. Proc. Natl. Acad. Sci. USA 101, 15736-15741 (2004). 
85. Gewirtz, A.T. et al. Lipoxin $\mathrm{A}_{4}$ analogs attenuate induction of intestinal epithelial proinflammatory gene expression and reduce the severity of dextran sodium sulfate-induced colitis. J. Immunol. 168, 5260-5267 (2002).

86. Serhan, C.N. et al. Novel functional sets of lipid-derived mediators with antiinflammatory actions generated from omega-3 fatty acids via cyclooxygenase 2-nonsteroidal antiinflammatory drugs and transcellular processing. J. Exp. Med. 192, 1197-1204 (2000).

87. Arita, M. et al. Resolvin E1 selectively interacts with leukotriene B4 receptor BLT1 and ChemR23 to regulate inflammation. J Immunol. 178, 3912-3917 (2007).

88. Sun, Y.P. et al. Resolvin D1 and its aspirin-triggered 17R epimer. Stereochemical assignments, anti-inflammatory properties, and enzymatic inactivation. J. Biol. Chem. 282, 9323-9334 (2007).

89. Hong, S., Gronert, K., Devchand, P.R., Moussignac, R.L. \& Serhan, C.N. Novel docosatrienes and 17S-resolvins generated from docosahexaenoic acid in murine brain, human blood, and glial cells. Autacoids in anti-inflammation. J. Biol. Chem. 278, 14677-14687 (2003).

90. Serhan, C.N. et al. Resolvins: a family of bioactive products of omega-3 fatty acid transformation circuits initiated by aspirin treatment that counter proinflammation signals. J. Exp. Med. 196, 1025-1037 (2002).

91. Schwab, J.M., Chiang, N., Arita, M. \& Serhan, C.N. Resolvin E1 and protectin D1 activate inflammation-resolution programmes. Nature 447 , 869-874 (2007).

92. Ariel, A. et al. Apoptotic neutrophils and T cells sequester chemokines during immune response resolution through modulation of CCR5 expression. Nat. Immunol. 7, 1209-1216 (2006).

93. Campbell, E.L. et al. Resolvin E1 promotes mucosal surface clearance of neutrophils: a new paradigm for inflammatory resolution. FASEB J. 21, 3162-3170 (2007).

94. Arita, M. et al. Resolvin E1, an endogenous lipid mediator derived from omega-3 eicosapentaenoic acid, protects against 2,4, 6 -trinitrobenzene sulfonic acid-induced colitis. Proc. Natl. Acad. Sci. USA 102, 7671-7676 (2005).

95. Kennedy, A.D. \& DeLeo, F.R. Neutrophil apoptosis and the resolution of infection. Immunol. Res. 43, 25-61 (2009).

96. Whyte, M.K., Meagher, L.C., MacDermot, J. \& Haslett, C. Impairment of function in aging neutrophils is associated with apoptosis. J. Immunol. 150, 5124-5134 (1993).

97. Kobayashi, S.D., Voyich, J.M., Whitney, A.R. \& DeLeo, F.R. Spontaneous neutrophil apoptosis and regulation of cell survival by granulocyte macrophage-colony stimulating factor. J. Leukoc. Biol. 78, 1408-1418 (2005).

98. Majno, G. \& Joris, I. Apoptosis, oncosis, and necrosis. An overview of cell death. Am. J. Pathol. 146, 3-15 (1995).

99. Ravichandran, K.S. Beginnings of a good apoptotic meal: the find-me and eat-me signaling pathways. Immunity 35, 445-455 (2011).

100. Watson, R.W. et al. Granulocytic differentiation of HL-60 cells results in spontaneous apoptosis mediated by increased caspase expression. FEBS Lett. 412, 603-609 (1997).

101. Salamone, G. et al. Promotion of neutrophil apoptosis by TNF-alpha. J. Immunol. 166, 3476-3483 (2001).

102. Cox, G. IL-10 enhances resolution of pulmonary inflammation in vivo by promoting apoptosis of neutrophils. Am. J. Physiol. 271, L566-L571 (1996).

103. Coxon, A., Tang, T. \& Mayadas, T.N. Cytokine-activated endothelial cells delay neutrophil apoptosis in vitro and in vivo. A role for granulocyte/ macrophage colony-stimulating factor. J. Exp. Med. 190, 923-934 (1999).

104. Lee, A., Whyte, M.K. \& Haslett, C. Inhibition of apoptosis and prolongation of neutrophil functional longevity by inflammatory mediators. J. Leukoc. Biol. 54, 283-288 (1993).

105. Le'Negrate, G., Rostagno, P., Auberger, P., Rossi, B. \& Hofman, P. Downregulation of caspases and Fas ligand expression, and increased lifespan of neutrophils after transmigration across intestinal epithelium. Cell Death Differ. 10, 153-162 (2003).

106. Lundqvist-Gustafsson, H. \& Bengtsson, T. Activation of the granule pool of the NADPH oxidase accelerates apoptosis in human neutrophils. J. Leukoc. Biol. 65, 196-204 (1999).

107. Watson, R.W., Redmond, H.P., Wang, J.H., Condron, C. \& BouchierHayes, D. Neutrophils undergo apoptosis following ingestion of Escherichia coli. J. Immunol. 156, 3986-3992 (1996).
108. Walzog, B., Jeblonski, F., Zakrzewicz, A. \& Gaehtgens, P. Beta2 integrins (CD11/CD18) promote apoptosis of human neutrophils. FASEB J. 11, 1177-1186 (1997).

109. Watson, R.W., Rotstein, O.D., Nathens, A.B., Parodo, J. \& Marshall, J.C. Neutrophil apoptosis is modulated by endothelial transmigration and adhesion molecule engagement. J. Immunol. 158, 945-953 (1997).

110. Brannigan, A.E. et al. Neutrophil apoptosis is delayed in patients with inflammatory bowel disease. Shock 13, 361-366 (2000).

111. Ina, K. et al. Increased mucosal production of granulocyte colonystimulating factor is related to a delay in neutrophil apoptosis in inflammatory bowel disease. J. Gastroenterol. Hepatol. 14, 46-53 (1999).

112. Noguchi, M., Hiwatashi, N., Liu, Z.X. \& Toyota, T. Increased secretion of granulocyte-macrophage colony-stimulating factor in mucosal lesions of inflammatory bowel disease. Digestion 63, 32-36 (2001).

113. Lampinen, M., Sangfelt, P., Taha, Y. \& Carlson, M. Accumulation, activation, and survival of neutrophils in ulcerative colitis: regulation by locally produced factors in the colon and impact of steroid treatment. Int. J. Colorectal Dis. 23, 939-946 (2008).

114. Wandall, J.H. Function of exudative neutrophilic granulocytes in patients with Crohn's disease or ulcerative colitis. Scand. J. Gastroenterol. 20, 1151-1156 (1985).

115. Hayee, B. et al. The neutrophil respiratory burst and bacterial digestion in Crohn's disease. Dig. Dis. Sci. 56, 1482-1488 (2011).

116. Curran, F.T., Allan, R.N. \& Keighley, M.R. Superoxide production by Crohn's disease neutrophils. Gut 32, 399-402 (1991).

117. Korzenik, J.R. \& Dieckgraefe, B.K. Is Crohn's disease an immunodeficiency? A hypothesis suggesting possible early events in the pathogenesis of Crohn's disease. Dig. Dis. Sci. 45, 1121-1129 (2000).

118. Smith, A.M. et al. Disordered macrophage cytokine secretion underlies impaired acute inflammation and bacterial clearance in Crohn's disease. J. Exp. Med. 206, 1883-1897 (2009).

119. Marks, D.J. et al. Defective acute inflammation in Crohn's disease: a clinical investigation. Lancet 367, 668-678 (2006).

120. Yamamoto-Furusho, J.K. \& Korzenik, J.R. Crohn's disease: innate immunodeficiency? World J. Gastroenterol. 12, 6751-6755 (2006).

121. Marks, D.J. et al. Inflammatory bowel disease in CGD reproduces the clinicopathological features of Crohn's disease. Am. J. Gastroenterol. 104, 117-124 (2009).

122. Assari, T. Chronic Granulomatous Disease; fundamental stages in our understanding of CGD. Med Immunol 5, 4 (2006).

123. Dinauer, M.C. The respiratory burst oxidase and the molecular genetics of chronic granulomatous disease. Crit. Rev. Clin. Lab. Sci. 30, 329-369 (1993).

124. Ament, M.E. \& Ochs, H.D. Gastrointestinal manifestations of chronic granulomatous disease. N. Engl. J. Med. 288, 382-387 (1973).

125. Marciano, B.E. et al. Gastrointestinal involvement in chronic granulomatous disease. Pediatrics 114, 462-468 (2004).

126. Werlin, S.L., Chusid, M.J., Caya, J. \& Oechler, H.W. Colitis in chronic granulomatous disease. Gastroenterology 82, 328-331 (1982).

127. Brown, J.R., Goldblatt, D., Buddle, J., Morton, L. \& Thrasher, A.J. Diminished production of anti-inflammatory mediators during neutrophil apoptosis and macrophage phagocytosis in chronic granulomatous disease (CGD). J. Leukoc. Biol. 73, 591-599 (2003).

128. Couper, R., Kapelushnik, J. \& Griffiths, A.M. Neutrophil dysfunction in glycogen storage disease lb: association with Crohn's-like colitis. Gastroenterology 100, 549-554 (1991).

129. Dieckgraefe, B.K., Korzenik, J.R., Husain, A. \& Dieruf, L. Association of glycogen storage disease $1 \mathrm{~b}$ and Crohn disease: results of a North American survey. Eur. J. Pediatr. 161, S88-S92 (2002).

130. Ishii, E., Matui, T., lida, M., Inamitu, T. \& Ueda, K. Chediak-Higashi syndrome with intestinal complication. Report of a case. J. Clin. Gastroenterol. 9, 556-558 (1987).

131. Lees, C.W., Barrett, J.C., Parkes, M. \& Satsangi, J. New IBD genetics: common pathways with other diseases. Gut 60, 1739-1753 (2011).

132. Reich, N.C. STAT3 revs up the powerhouse. Sci. Signal. 2, pe61 (2009).

133. Takeda, K. et al. Enhanced Th1 activity and development of chronic enterocolitis in mice devoid of Stat3 in macrophages and neutrophils. Immunity 10, 39-49 (1999).

134. Song, F. et al. Expression of the neutrophil chemokine $\mathrm{KC}$ in the colon of mice with enterocolitis and by intestinal epithelial cell lines: effects of flora and proinflammatory cytokines. J. Immunol. 162, 2275-2280 (1999). 
135. Kuhn, R., Lohler, J., Rennick, D., Rajewsky, K. \& Muller, W. Interleukin10-deficient mice develop chronic enterocolitis. Cell 75, 263-274 (1993).

136. Paul, G., Khare, V. \& Gasche, C. Inflamed gut mucosa: downstream of interleukin-10. Eur. J. Clin. Invest. 42, 95-109 (2012).

137. Kucharzik, T. et al. Acute induction of human IL-8 production by intestinal epithelium triggers neutrophil infiltration without mucosal injury. Gut 54, 1565-1572 (2005).

138. McCormick, B.A. et al. Surface attachment of Salmonella typhimurium to intestinal epithelia imprints the subepithelial matrix with gradients chemotactic for neutrophils. J. Cell Biol. 131, 1599-1608 (1995).

139. Mumy, K.L. \& McCormick, B.A. The role of neutrophils in the event of intestinal inflammation. Curr. Opin. Pharmacol. 9, 697-701 (2009).

140. Ina, K. et al. Mucosal interleukin-8 is involved in neutrophil migration and binding to extracellular matrix in inflammatory bowel disease. Am. J. Gastroenterol. 92, 1342-1346 (1997).

141. MacDermott, R.P. Chemokines in the inflammatory bowel diseases. J. Clin. Immunol. 19, 266-272 (1999).

142. Shea-Donohue, T. et al. Mice deficient in the CXCR2 ligand, CXCL1 (KC/GRO-alpha), exhibit increased susceptibility to dextran sodium sulfate (DSS)-induced colitis. Innate Immun. 14, 117-124 (2008).

143. Laan, M. et al. Neutrophil recruitment by human IL-17 via C-X-C chemokine release in the airways. J. Immunol. 162, 2347-2352 (1999).

144. Witowski, J. et al. IL-17 stimulates intraperitoneal neutrophil infiltration through the release of GRO alpha chemokine from mesothelial cells. J. Immunol. 165, 5814-5821 (2000).

145. Park, H. et al. A distinct lineage of CD4 T cells regulates tissue inflammation by producing interleukin 17. Nat. Immunol. 6, 1133-1141 (2005).

146. Fonseca-Camarillo, G., Mendivil-Rangel, E., Furuzawa-Carballeda, J. \& Yamamoto-Furusho, J.K. Interleukin 17 gene and protein expression are increased in patients with ulcerative colitis. Inflamm. Bowel Dis. 17, E135-E136 (2011).

147. Fujino, S. et al. Increased expression of interleukin 17 in inflammatory bowel disease. Gut 52, 65-70 (2003).

148. Hovhannisyan, Z., Treatman, J., Littman, D.R. \& Mayer, L. Characterization of interleukin-17-producing regulatory $T$ cells in inflamed intestinal mucosa from patients with inflammatory bowel diseases. Gastroenterology 140, 957-965 (2011).

149. Zhang, Z., Zheng, M., Bindas, J., Schwarzenberger, P. \& Kolls, J.K. Critical role of IL-17 receptor signaling in acute TNBS-induced colitis. Inflamm. Bowel Dis. 12, 382-388 (2006).

150. Ito, R. et al. Involvement of IL-17A in the pathogenesis of DSS-induced colitis in mice. Biochem. Biophys. Res. Commun. 377, 12-16 (2008).

151. Ogawa, A., Andoh, A., Araki, Y., Bamba, T. \& Fujiyama, Y. Neutralization of interleukin-17 aggravates dextran sulfate sodium-induced colitis in mice. Clin. Immunol. 110, 55-62 (2004).

152. Pelletier, M. et al. Evidence for a cross-talk between human neutrophils and Th17 cells. Blood 115, 335-343 (2010).

153. Halstensen, T.S., Mollnes, T.E., Garred, P., Fausa, O. \& Brandtzaeg, P. Epithelial deposition of immunoglobulin $\mathrm{G} 1$ and activated complement (C3b and terminal complement complex) in ulcerative colitis. Gastroenterology 98, 1264-1271 (1990).

154. Johswich, K. et al. Role of the C5a receptor (C5aR) in acute and chronic dextran sulfate-induced models of inflammatory bowel disease. Inflamm. Bowel Dis. 15, 1812-1823 (2009).

155. Chen, G. et al. Blockade of complement activation product C5a activity using specific antibody attenuates intestinal damage in trinitrobenzene sulfonic acid induced model of colitis. Lab. Invest. 91, 472-483 (2011).

156. Wang, D. \& DuBois, R.N. Eicosanoids and cancer. Nat. Rev. Cancer 10, 181-193 (2010).

157. Jupp, J. et al. Colonic expression of leukotriene-pathway enzymes in inflammatory bowel diseases. Inflamm. Bowel Dis. 13, 537-546 (2007).

158. Cuzzocrea, S. et al. 5-Lipoxygenase modulates colitis through the regulation of adhesion molecule expression and neutrophil migration. Lab. Invest. 85, 808-822 (2005).
159. Bertran, X. et al. Intracolonic administration of zileuton, a selective 5 -lipoxygenase inhibitor, accelerates healing in a rat model of chronic colitis. Gut 38, 899-904 (1996).

160. Mrsny, R.J. et al. Identification of hepoxilin A3 in inflammatory events: a required role in neutrophil migration across intestinal epithelia. Proc. Natl. Acad. Sci. USA 101, 7421-7426 (2004).

161. Cario, E. Toll-like receptors in inflammatory bowel diseases: a decade later. Inflamm. Bowel Dis. 16, 1583-1597 (2010).

162. Werts, C., Rubino, S., Ling, A., Girardin, S.E. \& Philpott, D.J. Nod-like receptors in intestinal homeostasis, inflammation, and cancer. J. Leukoc. Biol. 90, 471-482 (2011).

163. Anton, P.A., Targan, S.R. \& Shanahan, F. Increased neutrophil receptors for and response to the proinflammatory bacterial peptide formylmethionyl-leucyl-phenylalanine in Crohn's disease. Gastroenterology 97, 20-28 (1989).

164. Rabiet, M.J., Huet, E. \& Boulay, F. The N-formyl peptide receptors and the anaphylatoxin C5a receptors: an overview. Biochimie 89, 1089-1106 (2007).

165. Brown, A.J. et al. The Orphan G protein-coupled receptors GPR41 and GPR43 are activated by propionate and other short chain carboxylic acids. J. Biol. Chem. 278, 11312-11319 (2003).

166. Le Poul, E. et al. Functional characterization of human receptors for short chain fatty acids and their role in polymorphonuclear cell activation. J. Biol. Chem. 278, 25481-25489 (2003).

167. Sina, C. et al. G protein-coupled receptor 43 is essential for neutrophil recruitment during intestinal inflammation. J. Immunol. 183, 7514-7522 (2009).

168. Brinckerhoff, C.E. \& Matrisian, L.M. Matrix metalloproteinases: a tail of a frog that became a prince. Nat. Rev. Mol. Cell Biol. 3, 207-214 (2002).

169. Castaneda, F.E. et al. Targeted deletion of metalloproteinase 9 attenuates experimental colitis in mice: central role of epithelial-derived MMP. Gastroenterology 129, 1991-2008 (2005).

170. Baugh, M.D. et al. Matrix metalloproteinase levels are elevated in inflammatory bowel disease. Gastroenterology 117, 814-822 (1999).

171. Salmela, M.T. et al. Upregulation of matrix metalloproteinases in a model of $T$ cell mediated tissue injury in the gut: analysis by gene array and in situ hybridisation. Gut 51, 540-547 (2002).

172. Kruidenier, L., MacDonald, T.T., Collins, J.E., Pender, S.L. \& Sanderson, I.R. Myofibroblast matrix metalloproteinases activate the neutrophil chemoattractant CXCL7 from intestinal epithelial cells. Gastroenterology 130, 127-136 (2006).

173. Brandt, E. et al. The beta-thromboglobulins and platelet factor 4: blood platelet-derived CXC chemokines with divergent roles in early neutrophil regulation. J. Leukoc. Biol. 67, 471-478 (2000).

174. Wilson, C.L. et al. Regulation of intestinal alpha-defensin activation by the metalloproteinase matrilysin in innate host defense. Science $\mathbf{2 8 6}$, 113-117 (1999).

175. Swee, M., Wilson, C.L., Wang, Y., McGuire, J.K. \& Parks, W.C. Matrix metalloproteinase-7 (matrilysin) controls neutrophil egress by generating chemokine gradients. J. Leukoc. Biol. 83, 1404-1412 (2008).

176. Quinn, M.T., Ammons, M.C. \& Deleo, F.R. The expanding role of NADPH oxidases in health and disease: no longer just agents of death and destruction. Clin. Sci. (Lond.) 111, 1-20 (2006).

177. Faurschou, M. \& Borregaard, N. Neutrophil granules and secretory vesicles in inflammation. Microbes Infect. 5, 1317-1327 (2003).

178. Tjonahen, E. et al. Resolvin E2: identification and anti-inflammatory actions: pivotal role of human 5-lipoxygenase in resolvin E series biosynthesis. Chem. Biol. 13, 1193-1202 (2006).

179. Serhan, C.N. \& Petasis, N.A. Resolvins and protectins in inflammation resolution. Chem. Rev. 111, 5922-5943 (2011).

180. Weylandt, K.H., Kang, J.X., Wiedenmann, B. \& Baumgart, D.C. Lipoxins and resolvins in inflammatory bowel disease. Inflamm. Bowel Dis. 13, 797-799 (2007). 